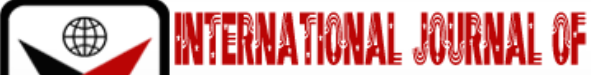

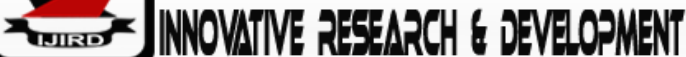

ISSN 2278-0211 (Online)

\section{Recommended Exercise Compliance among Noninsulin Dependent Diabetes Mellitus Patients at Jos University Teaching Hospital, Nigeria}

\begin{tabular}{|c|}
\hline $\begin{array}{c}\text { Gotodok Kopdima Hosea } \\
\text { Lecturer, Department of Nursing Science, University of Jos, Nigeria } \\
\text { Babayo M Tukur }\end{array}$ \\
Lecturer, Department of Nursing Science, University of Maiduguri, Nigeria \\
Abdulrahman Salisu Kombo \\
Lecturer, Department of Nursing Science, Ahmadu Bello University, Zaria, Nigeria \\
Bakari A Girei \\
Lecturer, Department of Medicine, Ahmadu Bello University, Zaria, Nigeria \\
Gaknung Bonji Kopdimma \\
Lecturer, Department of Nursing Science, University of Jos, Nigeria \\
Daniel Cletus Okpe \\
Lecturer, Department of Nursing Science, University of Jos, Nigeria \\
Wina Folashade \\
Lecturer, Department of Nursing Science, University of Jos, Nigeria \\
Ude Peter Adah \\
Lecturer, Department of Nursing Science, University of Jos, Nigeria \\
Aji M Gana \\
Lecturer, Department of Nursing Science, University of Maiduguri, Nigeria \\
Azi Bulus Samuel \\
Decturer, Department of Nursing Science, School of Nursing, Vom, Plateau State, Nigeria \\
Dauda Esther Dung \\
Lecturer, Department of Nursing Science, School of Midwifery, Jos, Plateau State, Nigeria \\
\end{tabular}

\section{Abstract:}

Background: The prevalence of Diabetes mellitus had increased dramatically during the last decades. Adherence to life-style changes such as recommended diet and physical exercise are important factors in achieving good control on Type 2 Diabetes and preventing its long-term complications. This study was carried out to examine the recommended Exercise compliance among Noninsulin Dependent Diabetes Mellitus Patients at Jos University Teaching Hospital, Plateau State. Method: A descriptive cross-sectional study design was used and a systematic sampling technique was utilized to select a sample of 130 for the study. Data was collected using a self-administered questionnaire and analysis was done using descriptive statistic by SPSS version 20 and chi-square was used to test the hypothesis at 0.05 significance level. Results: The findings revealed that 80(61.5\%) of the respondents were females, 39(30.0\%) were between 50-59 years, and 66(50.8\%) have family history of T2DM. 69(53.1\%) of the respondents have good knowledge of recommended exercise and 90(69.3\%) of the respondents do not comply with recommended exercise. Hypothesis tested showed that the p-value $=0.004$, significance level is 0.05 . Since the P-value is less than the significance level, null hypothesis which states that there is no significant association between duration of diabetes and adherence to recommended exercise is rejected. Conclusion: This study concludes that compliance to recommended exercise by type 2 diabetes mellitus patients is key to ensuring good glycemic index and prevention of complications. It is therefore recommended that health care providers (nurses) should health educate type 2 diabetes patients on self-care and its health benefit on their condition which will ensures good glycemic index, and health care providers (nurses) should follow them up to ensure that they practice recommended exercise which is key to ensuring that their blood glucose level is within the normal range.

Keywords: Diabetes mellitus, factors, recommended exercise, compliance, prevalence

\section{Introduction}

According to International Diabetes Federation (IDF) Atlas 9th edition (2019), roughly 463 million adults (20-79 years) were living with diabetes; by 2045 this figure is expected to reach 700 million, the number of people with type 2 diabetes is increasing in most countries. $79 \%$ of adults with diabetes were living 
underdeveloped and developing countries. 1 out of 5 people who are above 65 years old have diabetes. 1 in 2 (232 million) people with diabetes were undiagnosed. Diabetes mellitus account for 4.2 million deaths. At least United State dollar (USD) 760 billion dollars in health expenditure in $2019-10 \%$ of total spending on adults was on diabetes. More than 1.1 million children and adolescents are living with type 1 diabetes. More than 20 million live births ( 1 in 6 live births) were affected by diabetes during pregnancy and 374 million people are susceptible to developing type 2 diabetes (IDF Diabetes Atlas 9th Edition, 2019).According to the IDF Diabetes Atlas 9th Edition, 19 million adults (20-79) are suffering from diabetes in the IDF Africa Region in 2019. This figure is projected to reach 47 million by 2045. 45 million adults (20-79) in the IDF Africa Region have Impaired Glucose Tolerance (IGT) which predisposed them at high risk of developing type 2 diabetes. This figure is projected to reach 110 million by 2045. The IDF Africa Region has the greater percent of undiagnosed people of all IDF regions - 60\% of adults living with diabetes do not know they have it. Out of 9 birth, 1 is affected by hyperglycemia in pregnancy in IDF Africa Region. 9.5 billion USD was utilized on caring for people with diabetes in 2019-less than 1\% of the total global expenditure on diabetes (IDF Diabetes Atlas 9th Edition, 2019).

The widespread Type 2 diabetes mellitus in Nigeria has been high and is still increasing with the country reported as having the highest burden of diabetes in Africa (Ogbera, Ekpebegh, 2014). Almost 5 million people are still suffering from diabetes in Nigeria, and greater than 1.56 million cases of diabetes were realized in 2015. Also, 40,815 deaths in adults attributed to diabetes were attained (WHO, 2016).In Nigeria, diabetes was reported to comprise of $3-15 \%$ of medical admissions in most health facilities (Aguocha, Ukpabi, Onyeonoro, Njoku P and Ukegbu, 2013). People living with type2 diabetes are susceptible to various forms of both short- and long-term complications, which usually end in premature death (Chijioke, Adamu, Makusidi, 2010).Complications from diabetes can arise in different parts of the body and can increase the chances of premature death. Some complications that are likely to occur include heart attack, stroke, kidney failure, leg amputation, vision loss and nerve damage. Inadequate diabetes controlled in pregnancy lead to high risk of fetal death and other complications (WHO Global Report, 2010). Hyperglycemic control in type2 diabetes is key to preventing long-term micro- and macrovascular complications (American Diabetes Association, 2013).

Personal care plays a vital role in the management of type 2 diabetes mellitus. Personal care focuses on lifestyle changes (diet and physical activity), blood glucose monitoring, medication use, and foot and eye care. Dietary management plays a key role in personal care management as poor diets quality results to poor glucose control, and this is link with high-risk complications, disease rate and death rate (Mishali, Omer, Heymann, 2011).Adherence to a nutritious diet and common bodily train are methods to forestall or delay the onset of type2 diabetes (Diabetes key info, 2020). Moreover, getting half-hour of normal train per day (suppose brisk strolling, energy coaching, stretching train, and so forth.) a minimum of 5 days every week can hold blood glucose stage regular, and decrease the danger of growing diabetes by 35\% (Alhariri, Daud, Saghir, 2017).Practice of recommended diet and physical exercise are key factors in realizing good control on T2D and preventing complications. Adherence has been defined as person's obedience to taking medication, following a diet and or performs lifestyle changes correlate with agreed advice from a health care provider. Healthy dietary habits such as reduction in the consumption of high glycemic foods, fats and carbohydrates will lead to a decrease in the level of blood glucose, which will invariably reduce the quantity of needed insulin. Aerobic exercises help in reducing blood glucose levels, thereby reducing the concentration of insulin required and facilitates insulin activity (Shrivastava, Shrivastava, Ramasamy, 2013).

Some studies in Saudi Arabia revealed that management of diabetes among patients with T2D is poor (Almutairi, 2015, Al Johanietal., 2015), and obedience to American Diabetes Association (ADA) standards of care including personal care is grossly deficient (Harbi, 2015). According to the ADA, result driven diabetes management requires lifestyle modification to meet the patient-centered chronic care model of diabetic care (ADA, 2016). Drugs and behavioral changes to control type 2 diabetes and related conditions can only be effective through obedience to the overall recommended regimen. The World Health Organization (WHO) has shown that obedience to long-term therapy for chronic non-communicable illnesses in developed countries is around $50 \%$ on average (WHO, 2018).

Undesired health result and higher healthcare costs is realized when a patient does not obey suggested medication and behavioral changes such as exercise, smoking cessation or non-pharmacologic treatments such as physical therapy or dietary menu. It has been reported that treatment disobedience poses a special problem for diabetic children, adolescents and adults and thus will affect achievement of management goals unpleasantly, reduce treatment effectiveness and lead to frequent hospitalization, amputations and death (Eckland, 2013).

Good dietary habits, frequent physical activity and aerobic exercise help hinder or delay the onset of type 2 DM since such treatment promote and maintain glycemic control (WHO, 2018). Besides, obedience to 
lifestyle changes recommendations can ameliorate the disease burden and reduce the morbidity and mortality resulting from Type $2 \mathrm{DM}$ complications.

In view of the rate at which diabetes is increasing presently, particularly in developing countries and its associated complications (short-term and long-term), there is an urgent need for diabetic patients to obey prescribed diets and exercise and maintain their management regimen. This will help them to have desired management goals, slow the progress of diabetic complications and improve their quality of life (Kalyango, Owino \&Nambuya, 2008). Non-adherence to management regimen should therefore be a concern to all healthcare givers and all factors associated with it should be considered while caring for patients with diabetes.

Presently the cure for diabetes Mellitus is yet to be ascertain, however the key determinant in diabetes care is tight glycemic control which is achieved by compliance to prescribed medication, informed dietary changes, appropriate physical exercise and other instructions (Kalyango, Owino \&Nambuya, 2008; Eckland, 2013).

In clinical practice both in developed and developing countries, reports has shown that majority of type 2 diabetes patients had poor diabetes control due to non-compliance to management (Huther, Wolff \&Stange, 2013). Results showed that obedience by subjects were grossly inadequate, only $36.0 \%$ comply with medications and $25.4 \%$ with physical exercise and dietary instructions among type 2 diabetes was reported in South-South zone of Nigeria (John, Effiong, Okon Ekwere Essien, 2015).

Based on the researcher's observation on studies done on this topic in southern part of the country, the results revealed that most of the diabetes patients do no really adhere to life style modification, and wants to know the situation in Jos University Teaching Hospital, Plateau State, Nigeria which is the biggest referral Centre in the State. Also, the researcher observed that some adult patients with type 2 diabetes mellitus in medical ward were admitted or readmitted with uncontrolled high glucose levels and some of them have developed complications such as diabetic foot ulcer, heart attack, stroke, and loss vision and they are on diabetic medications. Hence this study on the factors affecting adherence to recommended diet and exercise among type 2 diabetes mellitus patients at Jos University Teaching Hospital (JUTH).

The objectives of the study;

- To assess the level of knowledge of recommended exercise among noninsulin dependent diabetes mellitus patients at JUTH.

- To determine the level of reported compliance with recommended exercise among noninsulin dependent diabetes mellitus patients at JUTH.

\subsection{Hypothesis}

There is no significant association between duration of diabetes and compliance with recommended exercise.

\section{Methodology}

\subsection{Research Design}

The research design adopted for this study is descriptive cross-sectional survey. A cross-sectional study is a type of research design in which data is collected from many different individuals at a single point in time. In cross-sectional research, you observe variables without influencing them.

\subsection{Study Setting}

The study was conducted at Jos University Teaching Hospital (JUTH), Plateau State. The study setting was selected purposively due to the fact that no studies have been conducted in this area on this topic and is the largest health care facility in the state.

The population used for this study consisted of type 2 diabetes mellitus patients aged 20 years and above men and women as well as the physically challenged who attended out-patient diabetic clinic within the study period. The total population of the study was 280. From this population, 142 were determined as the sample size using Yamane's formula for sample size determination. And a systemic sampling technique was used to select the 142 respondents.

\subsection{Instrument for Data Collection}

A self-administered questionnaire with closed ended questions in line with research questions was developed and used to obtain information from the respondents. The questionnaire comprises of three sections A, B and C. Section A elicits socio-demographic data of the respondents; Section B covers the knowledge of recommended exercises among noninsulin dependent diabetes mellitus. We conceptualized "knowledge on exercise recommendations" measures as follows: 14+ denotes good knowledge; a score of 8-12 represented fair knowledge while respondents who score below 8 were said to have poor knowledge. 
Section c covers level of compliance with recommended exercise among noninsulin dependent diabetes mellitus patients. Any participant who practices recommended exercise for 3 days and above has good practice level.

\subsection{Data Analysis}

Data collection was done over a period of 3 months after which all questionnaires were retrieved and were subsequently coded and analyzed using SPSS version 20 . Both descriptive and inferential statistics were used. Descriptive statistics in form of bar chat, frequency and percentage table while chi-square was used in testing the hypothesis generated.

\subsection{Ethical Consideration}

Permission for data collection was obtained from the Hospital ethical research committee Jos University Teaching Hospital (JUTH), Plateau State. Informed consent was obtained from each Participant prior to enrollment in the study. Patients were informed that they are allowed to withdraw from the study at any time without jeopardizing the care they are usually provided in the diabetic clinic.

\section{Results}

This chapter presents the findings of the study carried out on factors affecting adherence to recommended diets and exercise among type 2 diabetes mellitus patients at Jos University teaching hospital (JUTH). It consists of the results presented in frequency tables and percentage, figures, test of hypotheses and answers to research question.

\begin{tabular}{|c|c|c|c|}
\hline \multicolumn{2}{|r|}{$\begin{array}{c}\text { Variables } \\
\mathrm{N}=130\end{array}$} & Frequency & Percent \\
\hline \multirow[t]{3}{*}{ Gender } & & & \\
\hline & Female & 80 & 61.5 \\
\hline & Male & 50 & 38.5 \\
\hline \multirow[t]{5}{*}{ Age } & $30-39$ & 15 & 11.5 \\
\hline & $40-49$ & 20 & 15.4 \\
\hline & $50-59$ & 39 & 30.0 \\
\hline & $60-69$ & 36 & 27.7 \\
\hline & $70+$ & 20 & 15.4 \\
\hline \multirow[t]{5}{*}{ Marital Status } & Single & 5 & 3.8 \\
\hline & Married & 95 & 73.1 \\
\hline & Divorced & 5 & 3.8 \\
\hline & Widowed & 25 & 19.2 \\
\hline & Total & 130 & 100.0 \\
\hline \multirow[t]{7}{*}{ Educational Level } & None & 21 & 16.2 \\
\hline & non-formal & 14 & 10.8 \\
\hline & Primary & 20 & 15.4 \\
\hline & Secondary & 31 & 23.8 \\
\hline & Tertiary & 39 & 30.0 \\
\hline & Total & 125 & 96.2 \\
\hline & Total & 130 & 100.00 \\
\hline \multirow[t]{7}{*}{ Occupation } & civil servant & 32 & 24.6 \\
\hline & Pensioners & 20 & 15.4 \\
\hline & Farmer & 17 & 13.1 \\
\hline & Business & 41 & 31.5 \\
\hline & house wife & 19 & 14.6 \\
\hline & Student & 1 & .8 \\
\hline & Total & 130 & 100.0 \\
\hline \multirow[t]{4}{*}{ Religion } & Christianity & 84 & 64.6 \\
\hline & Islam & 45 & 34.6 \\
\hline & Others & 1 & .8 \\
\hline & Total & 130 & 100.0 \\
\hline \multirow{3}{*}{$\begin{array}{l}\text { Duration of the } \\
\text { Disease }\end{array}$} & $<10$ years & 93 & 71.5 \\
\hline & 10years+ & 37 & 28.5 \\
\hline & Total & 130 & 100.0 \\
\hline \multirow{3}{*}{$\begin{array}{c}\text { Family History of } \\
\text { DM }\end{array}$} & Yes & 66 & 50.8 \\
\hline & No & 64 & 49.2 \\
\hline & Total & 130 & 100.0 \\
\hline
\end{tabular}

Table 1: Socio-Demographic Data 
Table 1 above shows that among the type 2 diabetes mellitus patients, 50(38.5\%) are male while $80(61.5 \%)$ are female, $15(11.5 \%)$ are between the ages of 30-39 years, $20(15.4 \%)$ are between $40-49$ years, $39(30.0 \%)$ are between $50-59$ years, $36(27.7 \%)$ are between $60-69$ years while $20(15.4 \%)$ are 70 years and above, 5(3.8\%) are single, 95(73.1\%) are married, 5(3.8\%) are divorced while $25(19.2 \%)$ are widows, $21(16.2 \%)$ are without any form of education, $14(10.8 \%)$ have acquired non-formal education, $20(15.4 \%)$ have primary education, $31(23.8 \%)$ have secondary education while $39(30.0 \%)$ have tertiary education, $32(24.6 \%)$ are civil servants, $20(15.4 \%)$ are pensioners, $17(13.1 \%)$ are farmers, $41(31.5 \%)$ are business men, $19(14.6 \%)$ are house wife while $1(0.8 \%)$ is a student, $84(64.6 \%)$ are Christian, $45(34.6 \%)$ are Muslim while $1(0.8 \%)$ is a pagan, $93(71.5 \%)$ have been on treatment for less than 10 years while $37(28.5 \%)$ have been on treatment for more than 10 years, $66(50.8 \%)$ have family history of the diabetes mellitus while $64(49.2 \%)$ do not have the diseased family history.

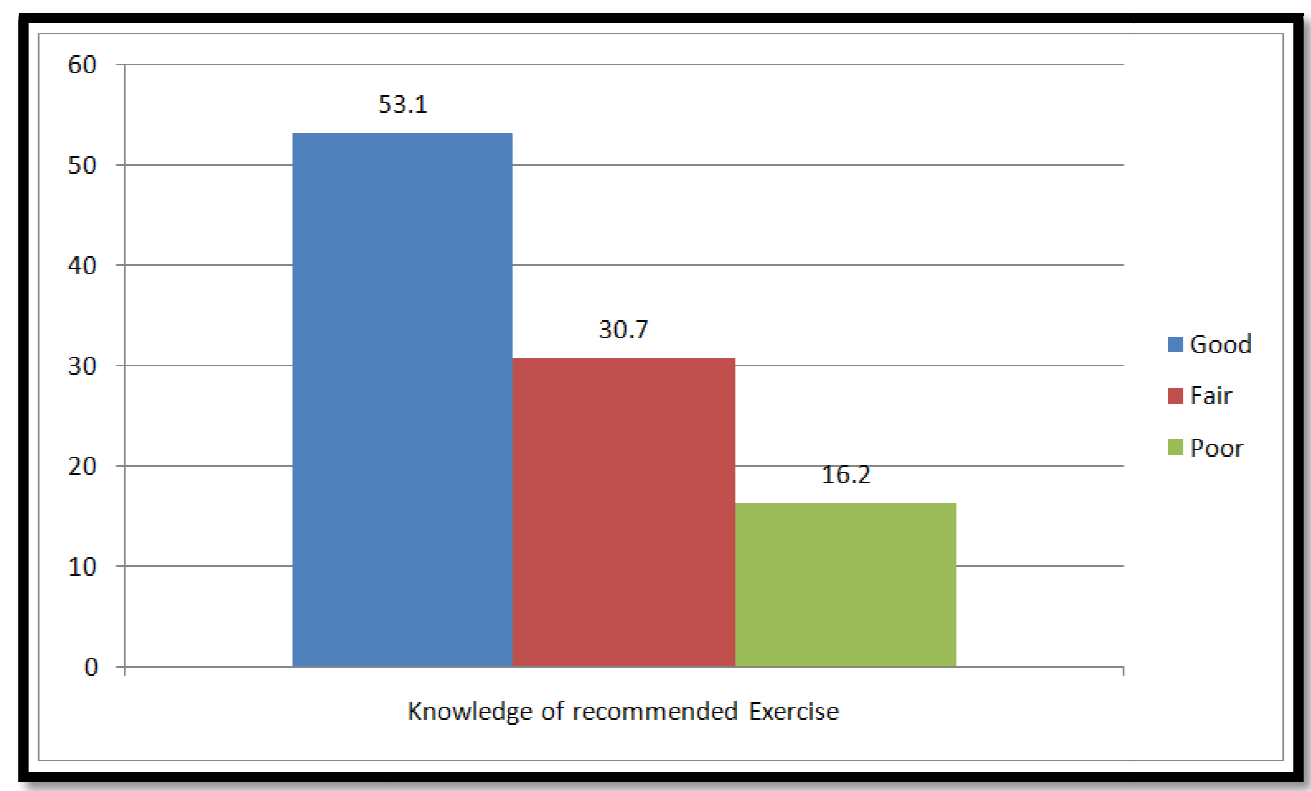

Figure 1: Knowledge of Recommended Exercise among Noninsulin Dependent Diabetes Patients

Figure 1 above shows that $69(53.1 \%)$ of the respondents have good knowledge of recommended, $40(30.7 \%)$ have fair knowledge while $21(16.2 \%)$ have poor knowledge.

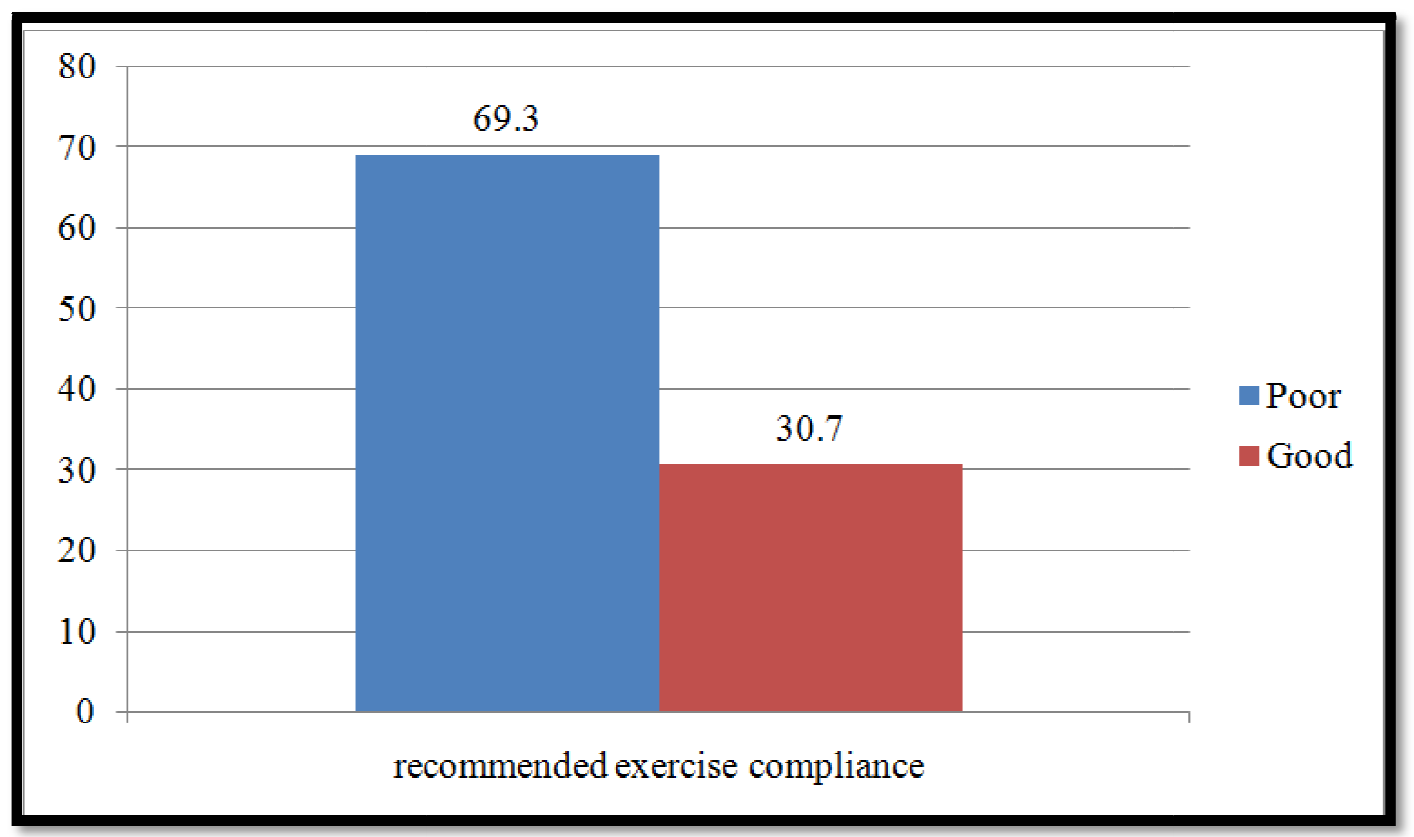

Figure 2: Level of Compliance with Recommended Exercise

Figure 2 above shows that $90(69.3 \%)$ of the respondents do not comply with recommended exercise while $40(30.7 \%)$ have good practice. 


\begin{tabular}{|c|c|c|}
\hline Variables & Frequency & Percentage \\
\hline Brisk walking & 67 & 51.5 \\
\hline Jogging & 14 & 10.7 \\
\hline Sports activities & 6 & 4.6 \\
\hline Bicycle/stationeries & 9 & 6.9 \\
\hline Swimming & 1 & 0.7 \\
\hline Stair climbing & 14 & 10.7 \\
\hline Hiking & 1 & 0.7 \\
\hline Gardening & 16 & 12.3 \\
\hline Free weight at gym & 2 & 1.5 \\
\hline Total & 130 & 100 \\
\hline
\end{tabular}

Table 2: Recommended Exercise

Table 2 above shows that $67(51.5 \%)$ of the respondents practice brisk walking, $14(10.7 \%)$ practice jogging, $6(4.6 \%)$ are into sports activities, $9(6.9 \%)$ ride bicycle, $1(0.7 \%)$ swim, $14(10.7 \%)$ climb stairs, $1(0.7 \%)$ go for hiking, $16(12.3 \%)$ work in the garden, $2(1.5 \%)$ carry free weight at gym while $1(0.7 \%)$ lift light objects.

\begin{tabular}{|c|c|c|c|}
\hline \multicolumn{2}{|c|}{ Variables } & Frequency & Percent \\
\hline \multirow{4}{*}{$\begin{array}{c}\text { Frequency } \\
\text { of practice }\end{array}$} & Once a week & 50 & 38.4 \\
\cline { 2 - 4 } & 2 days a week & 40 & 30.7 \\
\cline { 2 - 4 } & 3 days a week & 27 & 20.7 \\
\cline { 2 - 4 } & $\begin{array}{c}\text { 4 days and above a } \\
\text { week }\end{array}$ & 13 & 10 \\
\hline & Total & 130 & 100 \\
\hline \multirow{4}{*}{$\begin{array}{c}\text { Duration } \\
\text { of practice }\end{array}$} & $10-19$ mins & 23 & 17.7 \\
\cline { 2 - 4 } & $20-29$ mins & 41 & 31.5 \\
\cline { 2 - 4 } & 30 mins+ & 8 & 6.2 \\
\cline { 2 - 4 } Missing & Total & 57 & 55.4 \\
\hline Total & System & 58 & 44.6 \\
\hline
\end{tabular}

Table 3: Frequency of compliance with Recommended Exercise

Table 3 above shows that $50(38.4 \%)$ of the respondents practice recommended exercise once a week, $40(30.7 \%)$ practice 2 days a week, $27(20.7 \%)$ practice 3 days a week, while $13(10 \%)$ practice recommended exercise for 4 days in a week, $23(17.7 \%)$ of the respondents practice with recommended exercise for a period of between 10-19 minutes, 41(31.5\%) practice for a period of between 20-29 minutes, while 8(6.2\%) practice for 30 minutes and above.

\subsection{Hypothesis Testing}

\begin{tabular}{|c|c|c|c|}
\hline & Value & Df & Asymp. Sig(sided) \\
\hline Pearson chi-Square & 7.044 & 1 & .004 \\
\hline Continuity correction & 6.046 & 1 & .014 \\
\hline Likelihood Ratio & 7.041 & 1 & .004 \\
\hline Fisher's exact test & & & \\
\hline Linear-by-Linear association & 6.993 & 1 & .0015 \\
\hline N of valid cases & 130 & & \\
\hline
\end{tabular}

Table 4: Cross Tabulation between the Duration of Diabetes Mellitus and compliance with Recommended Exercise

Table 4 above shows the chi-square test result.The p-value $=0.004$, significance level is 0.05 . Since the $\mathrm{P}$-value is less than the significance level, null hypothesis which states that there is no significant association between duration of diabetes and compliance with recommended exercise is rejected. Hence there is a significant association between duration of diabetes and adherence to recommended exercise.

\section{Discussion of Findings}

This research study focuses on recommended exercise compliance among noninsulin dependent diabetes mellitus patients because of the increasing rate of complications associated with the disease. 
After data were collected, presented and analyzed, the research findings revealed that $(61.5 \%)$ of the respondents were female; (30.0\%) were between the ages of 50-59 years. This finding is in line with findings from research studies conducted by Umeh, Nkombua, Lushiku (2018) on knowledge and practice of lifestyle modification in patients with type 2 diabetes mellitus in Middelburg sub-district of Mpumalanga using an observational, descriptive and cross-sectional design. Data were collected from 150 patients using a selfadministered questionnaire. The results showed that the type 2 diabetes was predominant among females, people within 50- 59 years was more affected and almost $50 \%$ of the participants were obese with few $35 \%$ being overweight. Greater number (73.1\%) of them were married, majority $30.0 \%)$ of them have tertiary education, while most $(31.5 \%)$ of them were business men. Greater number $(64.6 \%)$ of them are Christian, most (70.5\%) of them have diabetes for less than 10 years, while majority (50.8\%) of them said that they have family history of the disease.

Findings from this study revealed that (53.1\%) of the respondents have good knowledge of recommended exercise. This finding disagrees with the findings of Okonta, Ikombele\&Ogunbanjo (2014) in their study on topic knowledge, attitude and practice regarding lifestyle modification, a cross-sectional study using a structured questionnaire. Their results revealed that out of the 217 participants, most respondents $(92.2 \%)$ had inadequate knowledge of the benefits of exercise, weight loss and a healthy diet. This is because their study was conducted in different area, with greater sample size and remoteness of the area, although the same design and similar questionnaire was used. Also, findings from Hayahabou\& Heba (2016) on the Knowledge, attitude and practice of diabetic patients (type II) regarding life style modification at Qena University Hospital in Upper Egypt using questionnaire which assessed 150 type 2 diabetic patients showed that most of the participants had poor knowledge regarding the benefits exercise and $84 \%$ had poor knowledge regarding a healthy diet. On the other hand, this researcher finding is in line with the result of John (2014) in his study on knowledge of the role of diet and exercise recommendations and factors associated with nonadherence to diet and exercise among type 2 diabetes patients at Kenyatta national hospital diabetic clinic showed that most $83.95 \%$ of the participants understood lifestyle modifications in diabetic therapy as both exercise \& dietary habit. Most $87.04 \%$ \& $96.30 \%$ of the participants perceived that diet \& exercise control sugar level with majority $95 \%$ of them not complying to recommended diet and exercise.

Findings from this study revealed that majority $(69.3 \%)$ of the respondents do not complied with recommended exercise with most (60.4\%) of them being females and among the exercise recommendations, most (49.6\%) of them participated in brisk walking and majority (42.3\%) of them exercises often for a period of 20-29 mostly (31.5\%). Statistically significant finding revealed that most of the participants who did not adhere to exercise recommendations had poor glycemic control. This finding agrees with the findings from research studies conducted by Umeh, Nkombua, Lushiku (2018) on knowledge and practice of lifestyle modification in patients with type 2 diabetes mellitus in Middelburg sub-district of Mpumalanga using an observational, descriptive and cross-sectional design. Data were collected from 150 patients with type 2 diabetes mellitus (T2DM) using a self-administered questionnaire. The results revealed that most of the respondents do not participated in exercises and majority (59\%) of them preferred brisk walking. A statistically finding showed that most $79.63 \%$ of participants who did not comply to exercise recommendations had poor glycemic control. Obesity (47.52\%) and overweight (32.67\%) were responsible for poor glycemic control. These two findings are similar probably because the study design was used with almost the sample size and similar instrument even though they were conducted in different locality.

The result of the test of hypothesis using $\mathrm{X}^{2}$ revealed that the $\mathrm{p}$-value $=0.004$, significance level is 0.05 . Since the P-value is less than the significance level, null hypothesis which states that there is no significant association between duration of diabetes and adherence to recommended exercise is rejected, leading to the conclusion that there is a significant relationship between the duration of type 2 diabetes mellitus and practice of recommended exercise.

\section{Conclusion}

Based on findings from this study, it was concluded that type 2 diabetes mellitus patients at Jos University Hospital have good knowledge of recommended exercise but their level of compliance with recommended exercise is poor.

\section{Recommendations}

- It was recommended that health care providers should emphasize on self-care and its health benefit on diabetes patients which will ensures good glycemic index.

- It was recommended that Jos university teaching Hospital management should make blood glucose screening mandatory and free to all patients on admission as this will go a long way in reducing the danger associated with diabetes mellitus. 
- It was recommended that a study should be conducted among type 2 diabetes patients on the impact of health education that will enhance the practice of recommended exercise

\section{References}

i. Abdullah Alhariri, FaizDaud, Sultan Ayesh Mohammed Saghir (2017): Factors associated with adherence to diet and exercise among type 2 diabetes patients in Yemen. Diabetes Manag (2017) 7(3), 264-271

ii. Al Johani, K, Kendall, G. and Snider, P (2015): Self-Management Practices among Type 2 Diabetes Patients Attending Primary Health-Care Centres in Medina, Saudi Arabia. Eastern Mediterranean Health Journal; 21:621-628. https://doi.org/10.26719/2015.21.9.621

iii. Almutairi KM (2015): Quality of Diabetes Management in Saudi Arabia: A Review of Existing Barriers. Arch Iran Med; 18:816-821.

iv. American Diabetes Association (2019): Living with diabetes. Diabetes.org. Retrieved from http://www. diabetes.org/living-with-diabetes/

v. American Diabetes Association (2016): Standards of Medical Care in Diabetes. Diabetes care 2016; 39 Suppl 1: S1-106.

vi. Chijioke A, Adamu AN, Makusidi AM (2010): Mortality patterns among type 2 diabetes mellitus patients in Ilorin, Nigeria. JEMDSA; 15: 79-82.

vii. Diabetes key info; (2020): Obtainable from: https://www.who.int/news-room/factsheets/element/diabetes. Accessed February23, 2021.

viii. Eckland, K. (2013): The newest epidemic: medication non-adherence. AmericanJournal of Management care, 18 (3); 49-54.

ix. Forouhi NG, Misra A, Mohan V, et al (2018): Dietary and dietary approaches for prevention and administration of sort2 diabetes. BMJ: 361: k2234. doi:10.1136/bmj.k2234

x. Global report on diabetes. Geneva: World Health Organization; (2016): IDF Diabetes Atlas. 8th Edition. Brussels: International Diabetes Federation, 2017.

xi. Harbi TJA, Tourkmani AM, Al-Khashan HI, Mishriky AM, Qahtani HA, Bakhiet A (2015): Adherence to the American Diabetes Association standards of care among patients with type 2 diabetes in primary care in Saudi Arabia. Saudi Medical Journal; 36:221-227.

xii. Hayahabou E. I \&Heba A. O, (2016): Knowledge, attitude and practice of diabetic patients (type II) regarding life style modification at Qena University Hospital in Upper Egypt: Journal of Health, Medicine and Nursing Vol.27. ISSN 2422-8419 An International Peer-reviewed Journal

xiii. Huther, J. Wolff, A., Stang, D. (2013): Incomplete Medication Adherence of chronically ill patients in German Primary care. Patient Prefer Adherence. 2013;7:237-244

xiv. International Diabetes Federation (2019): Diabetes Atlas $8^{\text {th }}$ e edition: Global estimates of diabetes prevalence for 2017 and projections for 2045.

xv. Jadawala HD, Pawar AB, Patel PB, Patel KG, Patel SB, Bansal RK (2017): Factors Associated withNonAdherence to Diet and Physical Activity among Diabetes Patients: A Cross Sectional Study. Intl J Community Med; 8(2):68-73.

xvi. John, M.E, Effiong, M.U, Essien, and O.E, (2015): Compliance and glycemic control in adult diabetes in rural Nigeria. Nursing Research and Development 4(1): 27-31

xvii. Kalyango J.N, Owin O.E, Nambuya A.P, (2008): Non adherence to diabetes treatment at Mulago Hospital in Uganda: Prevalence and associated factors: African Health Sciences 8(2):67-73. Retrieved $1 / 25 / 2010$

xviii. Mishali M, Omer H, Heymann AD (2011): The importance of measuring self-efficacy in patients with diabetes. FamPract.; 28 (1):82-87.

xix. Ogbera A 0, Ekpebegh C (2014): diabetes mellitus in Nigeria; The past, present \& future. World J Diabetes.5; 905-11.

xx. Okonta, H. I., Ikombele, J. B., \&Ogunbanjo, G. A. (2014): Knowledge, attitude and practice regarding lifestyle modification in type 2 diabetic patients. African Journal of Primary Health Care \& Family Medicine, 6(1), 655.

xxi. Parajuli J, Saleh F, Thapa N, Ali L (2014): Factors associated with nonadherence to diet and physical activity among Nepalese type 2 diabetes patients; a cross sectional study. BMC Research Notes; 7:758. Doi: 10.1186/1756-0500-7-758

xxii. Shrivastava S, Shrivastava PS, Ramasamy J. (2013): Role of self-care in management of diabetes mellitus. J. Diabetes Metab. Disord. 12(1), 14 
xxiii. Umeh, A.E.; Nkombua, Lushiku (2018): knowledge and practice of lifestyle modification in patients with type 2 diabetes mellitus in Middelburg sub-district of Mpumalanga. South African Family Practice 2018; 60(1):26-30.

xxiv. World Health Organization (2016): Global Report on Diabetes. Geneva (Accessed 30 August 2016).

xxv. World Health Organization (2018): Global Report on Diabetes. (Accessed 30 August 2018). 